\title{
Investigation of temperature effect on the electrical conductivity of alcohol solutionssodium and potassium alcoholates
}

\author{
(C) Vera A. Petrukhina, Pavel I. Fedorov, Ksenia A. Konnova, \\ Maria V. Yakimova, and Nikolay I. Koltsov* ${ }^{+}$ \\ Department of Physical Chemistry and Macromolecular Compounds \\ Chuvash State University of I.N. Ulyanov. Moskovsky ave., 15. Cheboksary, 428015. \\ Chuvash Republic.Russia.Phone: (8352) 45-24-68.E-mail: koltsovni@mail.ru
}

\begin{abstract}
*Supervising author; ${ }^{+}$Corresponding author
Keywords: solutions sodium and potassium alcoholates, specific and equivalent electrical conductivity, temperature, Arrhenius equation.
\end{abstract}

\begin{abstract}
Earlier, we studied the electrical conductivity of inorganic salts in a number of alcohols (ethanol, propanol-2, and butanol-1) at room temperature and found that alcoholic solutions of inorganic salts are weak electrolytes. It is known that an increase in the temperature of salt solutions leads to an increase in electrical conductivity due to an increase in the mobility of their ions in the solvent medium. To study the temperature dependence of the electrical conductivity of aqueous solutions of electrolytes, we proposed an approach based on the study of the effect of temperature on the equivalent electrical conductivity of solutions at infinite dilution $\lambda_{\infty}$. Using this approach, we studied the electrical conductivity of aqueous solutions of a number inorganic salts (nitrates, acetates, and phosphates), carboxylic acids, and amino acids as a function of temperature. It was found that for these solutions the dependence $\lambda_{\infty}(T)$ is described by the exponential Arrhenius equation $\lambda_{\infty}=\mathrm{A} \cdot \exp (-\mathrm{E} /(\mathrm{RT}))$. This equation was used to describe the temperature dependence of the ultimate equivalent conductivity for solutions of a number of inorganic salts (calcium and nitrate calcium, cadmium, lithium and potassium iodides, chloride, iodide and ammonium nitrate, silver nitrate and sodium bromide) in ethanol. This article investigated and demonstrated the possibility of describing the experimental data $\lambda_{\infty}(T)$ for solutions of ethylates, propylates and isopropylates of sodium and potassium in the corresponding alcohols (ethylates in ethanol, propylates in propanol, isopropylates in isopropyl alcohol) using the same equation.
\end{abstract}

\section{References}

[1] V.A. Petruhina, T.A. Kurnaleva, D.A. Egorova, and N.I. Koltsov. Investigation of the influence of temperature on electrical conductivity of aqueous solutions of electrolytes. Part 1. Strong electrolytes. Butlerov Communications. 2016. Vol.45. No.1. P.107-109. DOI: 10.37952/ROI-jbc-02/16-45-1-107

[2] V.A. Petruhina, T.A. Kurnaleva, D.A. Egorova, A.S. Vasileva, and N.I. Koltsov. Investigation of the influence of temperature on electrical conductivity of aqueous solutions of electrolytes. Part 2. Weak electrolytes. Butlerov Communications. 2016. Vol.45. No.1. P.110-112. DOI: 10.37952/ROI-jbc-02/16-45$1-110$

[3] V.A. Petrukhina, E.V. Andreeva, and N.I. Koltsov. Investigation of the influence of temperature on electrical conductivity of aqueous solutions of electrolytes. Part 3. Nitrates. Butlerov Communications. 2017. Vol.49. No.1. P.104-107. DOI: 10.37952/ROI-jbc-02/17-49-1-104

[4] V.A. Petrukhina, E.V. Andreeva, and N.I. Koltsov. Investigation of the influence of temperature on electrical conductivity of aqueous solutions of electrolytes. Part 4. Acetates and phosphates. Butlerov Communications. 2018. Vol.53. No.2. P.140-144. DOI: 10.37952/ROI-jbc-02/18-53-2-140

[5] E.N. Egorov, N.F. Ushmarin, S.I. Sandalov, I.S. Spiridonov, and N.I. Koltsov. The influence of functional ingredients on the technological properties of oil swelling rubber sealing elements. Butlerov Communications. 2018. Vol.54. No.5. P.159-164. DOI: 10.37952/ROI-jbc-02/18-54-5-159

[6] V.A. Petrukhina, P.I. Fedorov, T.A. Kirillova, L.Yu. Tcareva, E.V. Andreeva, and N.I. Koltsov. Study of the effect of temperature on the electrical conductivity of aqueous solutions of amino acids. Butlerov Communications. 2019. Vol.57. No.1. P.91-94. DOI: 10.37952/ROI-jbc-02/19-57-1-91 
[7] V.A. Petrukhina, T.A. Kirillova, L.Yu. Tcareva, E.V. Andreeva, and N.I. Koltsov. The study of electrical conductivity of spirit solutions of salts. Butlerov Communications. 2019. Vol.57. No.1. P.154-158. DOI: 10.37952/ROI-jbc-02/19-57-1-154

[8] V.A. Petrukhina, K.A. Konnova, M.V. Yakimova, and N.I. Koltsov. Investigation of temperature effect on the electrical conductivity of solutions inorganic salts in ethanol. Butlerov Communications. 2020.

Vol.61. No.1. P.76-80. DOI: 10.37952/ROI-jbc-02/20-61-1-76 